\title{
Effect of Communicative Competence in English Over Evolving Job Roles of CPEC: A Critical Analysis of Pakistani Labor Market
}

\author{
Ali Anwer ${ }^{1} \&$ Aneela Gill ${ }^{1}$ \\ ${ }^{1}$ National University of Modern Languages, Pakistan \\ Correspondence: Ali Anwer, National University of Modern Languages, Pakistan. E-mail: \\ theswati@hotmail.com
}

Received: April 3, 2020

Accepted: May 20, $2020 \quad$ Online Published: June 2, 2020

doi:10.5539/ijel.v10n4p171

URL: https://doi.org/10.5539/ijel.v10n4p171

\begin{abstract}
This research paper critically analyses the Pakistani job market and evaluates the importance of communicative competence in over the realization of the job potential of employees working on the CPEC (China Pakistan Economic Corridor) project. The CPEC project is a multi-dimensional infrastructure-based project that has injected Pakistan with not only great economic potential but also with a multi-lingual work force with a diverse cultural capital. This multi-lingual work force requires better communication standards to function as teams and this study tries to evaluate the effect communicative competence on the careers of employees in this sector. The paper conducted surveys from 10-15 major companies associated with the CPEC project and anonymous employee responses were collected. Data were analyzed qualitatively using strategic competence framework of Canale and Swain (1980). The study found that team leaders that were competent communicators yielded better results from their perspective teams and had higher levels of employee satisfaction. Furthermore, study revealed that people skilled in communication skills had higher chances of career growth and progress as compared to technically skilled personnel.
\end{abstract}

Keywords: communicative competence, job roles, CPEC

\section{Introduction}

Linguistically speaking, Pakistan has been a complex society with the amalgamation of hundreds of dialects and dozens of separate languages mixing together. Initially, the spread of the English language in the sub-continent and thereby Pakistan as well was due to the colonial expansion of the British into the sub-continent and the linguistic annexation of the English language over formal bridges of communication. The British effectively marginalized and controlled the cultural capital of the sub-continent by the subjugation of linguistic freedom and restructuring of official means of communication to an English medium. This form of annexation had far-reaching effects into the linguistic capital and in essence, the cultural capital of the colonies that branched into separate countries. Therefore, it is quite natural to observe that while the official language of Pakistan, which is followed in all formal forms of communication over written and oral means, is English (Black, 2010). But, in a perplexing irony, almost all non-formal forms of communication are carried out in local languages and regional languages which vary in accordance with the setting being rural or urban. While a rural setting or a situation that calls for two interlocutors to be in a rural connection is usually carried out in the form of regional languages which can be Pashto, Hindko, Sindhi or Baluchi with many dialects-based variants. On the other hand, this very register varies in urban settings where almost all major cities and towns observe Urdu as a medium of daily communication.

This division of various kinds of cultural divides presents schizophrenia of various communicative mediums in most settings in Pakistan, but perhaps the most important setting of such communication is identified as the corporate setting where the formal medium of communication is English but the lingua franca (Urdu) is not used as often. It is observed that the spoken English communication is used as a form of establishing competence in the work environment and this measure of evaluation of competence is causing a shift in the workplace's linguistic scenario, as people shift towards English language as a form of lingua franca. The study of this process is especially important since it allows the determination of trends of modern job requirements and the processes that are employed to evaluate the employees for promotions. Furthermore, since employees are shifting towards this form of English based communication, which is not their L1 language, linguistic barriers and 
miscommunication is becoming a serious problem in the corporate sector. This form of evaluation of employees burdens the average person and causes the communication process to be broken due to linguistic barriers between the participants. According to a research based in the US and UK, about \$37 billion dollars' worth of losses were reported by businesses due to miscommunication between employees.

\section{Research Question}

Some of the most important research questions addressed by the research paper would be:

"Does Communicative Competence and English Language Play a role in Job Success in Pakistan? Is it important in realization of CPEC?"

\section{Literature Review}

Many studies have been conducted over the possible relation between communication and language in the context of organizations and teams. A vast number of these studies have been focused on the individual unit or team member's competence in communication instead of the entire communication paradigm in general. These studies have utilized the research focus keeping in mind that the official language of the organization is often not the regional or native language of the population in question. In fact, Pakistan is one of the few countries that provide this unique hurdle to the corporate culture where the regional languages, lingua franca and official language are all different from each other. This research believes that language plays a significant role in the job performance and the progress of a career in the Pakistani job market and has a deep influence in the managerial capability of an individual working in mega projects with multi-lingual work force (Blasková, 2010).

Organizations these days have to deal with global communication and therefore, the work force is often composed of individuals with a diverse skills and knowledge base; the organizations which have the capability to hone and develop these skills in their employees are able to outperform the organizations that are not able to utilize these skills, and often lack the proper organization and coordination.

The coordination of these various skills, be it technical or otherwise, requires a proper medium of communication. This medium of communication needs to be defined for both written and oral forms of various employee-employer interactions or other inter-company flow of information between various participants. Luo and Shankar (2006) have worked on models of communication that operate in companies that have their offices set up in foreign countries tend to have a multi-lingual work force, operating in a multi-cultural setting (Canale, 1983). The managers in such settings have to deal with registering a language choice that is easily able to balance the integration of a multi-cultural environment without compromising on the flow of communication between different parts of the work force. This balance of local adaptation with international integration is extremely important (Canale, 1980). The building of relationships in organizations and teams working on megaprojects can only stem from effective communication and the establishment of such work channels demands a certain level of competence from the interlocutors. These relationships have been shown to have an impact over the organization and the project performance as well (Chakravarthy, 1986).

Similarly, work environments that require the establishment of multi-lingual work force scenario are particularly influenced by the communication of the managers and team leads. Reclusive team leads which often have an autocratic or goal-based leadership style are not able to deliver well with these kind of team settings (Canale, 1983). Especially considering global team scenarios, team leads are expected to lead teams that have global team characteristics which include demography, skill and culture while language is essential component of culture.

Marschan's (1997) research indicates that team members are more likely to perform and show commitment in companies and work places which allow for effective communication within the teams, which is indeed a function of the team lead's communicative competence itself. Tsui and Tollefson (2008) have identified the English language to be a tool of personal development that has been extensively used in the multinational work place for achieving national goals and organizational goals as well.

Research by Bourdieu (1977) demonstrates that the English language is one of the most important and marketable skills in the work place that is required for adaptation in a fast-paced technological development. With the advancement in technology, companies have adapted towards new forms of communicative tools, often based on internet and cloud-based services. These cloud-based services are precursors of the modern forms of fast-paced communication that poses new challenges in terms of communicative competence of managers with their respective teams with the added speed that seemed almost unimaginable a few years back.

Research by Trimbron (2010) indicates that English language is one of the most important factors of organizational success and insufficient command over the English language can hamper the progress of the individual over the organization's framework. Similarly, research by Talbot (2009) also indicates that the English 
language is not only the language of communication but also the language used for trade and the acquisition of knowledge.

According to Light's (1989) definition, communicative competence is defined as the "relative and dynamic, interpersonal construct based on functionality and adequacy of communication and sufficiency of knowledge, judgment and skill in four interrelated areas comprises linguistic competence, operational competence, social competence and strategic competence. Linguistic and operational competencies refer to knowledge and skills in the use of the tools of communication; social and strategic competencies reflect function knowledge in interaction".

Similarly, communicative competence, as explained by Spitzberg (1988) defined communicative competence as the ability of an individual to be able to interact "well" with others. This term "well" was further elaborated by Spitzberg as the accuracy, clarity, comprehensibility, coherence, expertise, effectiveness and appropriateness involved in the delivery of speech. Communicative Competence in essence was defined as the person's competence and ability in illicit and tacit knowledge that was used to language usage. Furthermore, communicative competence is further elaborating as linguistic competence (Chomsky, 1969).

Hymes (1972) defined communicative competence as the ability of a speaker to communicate the message correctly in order to achieve the communication goal of the intercourse between the interlocutor and the audience. This definition of communicative competence by Hymes is rudimentary and was altered by researchers like Swain (1980) and Canale but since the core application of communicative competence in this research paper is the application over managerial roles, therefore, this original definition of competence can suffice (Burešová, 2015).

Ahmed's (2013) research over the communicative language teaching in Pakistan demonstrated that while the Pakistani education sector is primarily focused over the generation of educated individuals with the expertise in their domain, no special effort is conducted over the communicative competence of the individuals in their professional education (Deshpandé, 1993). Furthermore, the English language teaching of the individuals is limited to semantics, classical literature and compositional form of English. No special effort is made during the design of the ELT courses to cater for the communicative aspect of functional English required for everyday business and corporate sector communication. Due to this particular aspect, the Pakistani corporate sector faces dire issues with the collection of work force that is competent in competition with the global market. Many of the technically sound professionals have faced issues in the competition for jobs due to their inherent lack of communicational skills in the job market (Bourdieu, 1991).

The CPEC project is one of the most important projects of Pakistan, which has injected more than $\$ 46$ billion dollars into the country's economy and is directly associated with the development of various sectors in Pakistan. Under these different mega projects, other small-scale projects are running such as infrastructure, transportation infrastructure, power plants, orange line, KKH-II, and other developmental projects. China supports the government of Pakistan in educational sector by providing financial support.

CPEC highly focused on infrastructural development in Pakistan. The major interest of China in Pakistan is to connect with the world through Gwadar port. It will help China to become the superpower. The China-Pakistan Economic Corridor is one of the biggest mega projects of road infrastructure right now and perhaps is one of the most fast-paced projects in the world as well (Chughtai, 2008). The total parallel processing of multi-faceted projects makes this whole mega-project a computational and managerial nightmare with very little chance of delays not choking the project. Therefore, the project requires a really well-developed communication strategy that is not choked due to the lack of communicative competence of the employees working in the sector (Chow, 2000). It is also worth mentioning that the project is also bringing in the Chinese work force which has no prior experience with the Pakistani cultural setting. The seam-less integration of this foreign work force into the CPEC project requires a level of competence from its leaders that has not been expected out of the traditional work settings in the Pakistani job sector (Chughtai, 2008).

Research has been conducted over the far reaching consequences of the establishment of the CPEC project in Pakistan, relating the geo-political importance of the project in the context of Asian-bloc being established by China, and the effects of the cultural integration of the incoming Chinese worker population in the Pakistani setting, but no factual research has been conducted over the possible communicational hurdles faced by the managerial team leads of the project dealing with not only a linguistically diverse work force but also a work force that has been injected with an alien element into it, driving a challenging transformation during the work flow itself (Crystal, 2012). This current study aims to determine the analysis of the effect of communicative competence in English on effective management of CPEC project and the employee promotion through ranks. 
The analysis is focused on the managerial level employees working in the CPEC project of all national regions in Pakistan.

The role of language in the corporate sector is not only limited to the technical problems, but rather is considered as an important factor during the considerations of their promotions and appointments and assignments to different projects. Similarly, during the assignment of managers to certain projects, the managerial and leadership talent of the individual is gauged, the key aspect of which is the lingusitc communicative competence of that individual over traditional job roles such as managing labour based teams, small teams and large project-based management (Deshpandé, 1993). Therefore, the importance of communication be it in English or other linguistic medium is vital for the effective flow of information, orders and feedback within the company (Dhir, 2005). Many companies opt for English language as their key medium of communication due to the global diversity it offers as a medium of communication as well as the factoring in of company communication with global suppliers, clients etc. On the other hand, the CPEC project is uniquely different from these other strategies since it employs a demographic that is mostly filling in labour roles for infrastructure projects (Edirisingha, 2007). These labour roles are filled in by both Chinese and Pakistani labourers from various regional areas and backgrounds. Expectation of a cohesive work force design requires the research into the strategies of communicative competence and lingusitc ability required for practice in this leadership scenario.

Most of the work force working in CPEC project is from the Pakistani Engineering community. According to Committee on the Engineer of 2020 (2005), engineering graduates working in this particular field need to be well aware of some of the key problems associated with effective communication in the field, managing and leading work forces (Burda, 1996). In the CPEC scenario, the engineers from both Pakistan and China would need to be well-equipped with the communicative skills required for the engineering presentations, skills, discussions, conversations, negotiations and client communications, which are part of the everyday project realization requirement.

\section{Methodology}

The methodology used for the research conducted for this research paper was a mixed-method approach that used both qualitative and quantitative aspects of research. Qualitative research was carried out on the development of definition of communicative competence which was drawn from the previous research. Since the data over the application of such communicative competence over Pakistani corporate sector was lacking, especially considering the leadership styles followed in the said corporate sector, therefore, the survey questionnaires were distributed over 10 major companies associated with CPEC program and the responses of employees were collected anonymously. The web-link of the survey was distributed to 15 employees and shared in their company groups and about 93 anonymous responses were collected. These responses were then tabulated and researched using Excel to get an idea about the communication path followed by most leaders in Pakistani job sector and the need for communicative competence.

\subsection{Sample Population}

The sample population was taken from a pool of 15 companies associated with the CPEC project and the responses were collected from the employees in general (considering the managers, team leads and low-tier employers alike) to get a better understanding of the various processes that were involved in the communication tiers between employee-employer interaction of various groups. In this manner, the results about the leadership, role of English language and opinions about the importance of the English language as a communicative medium were not centralized over a specific pool of employees (of lower or upper management employees), but could be generalized for the entire corporate culture of the companies involved.

\subsection{Tools Involved}

- $\quad$ Microsoft Excel

- Google Forms Survey Collector

- Facebook Forums and Employee Social Communication

- Graph Plotters and Interactive Chart Generator

\subsection{Datasets}

The datasets which have the answers collected from the employees from the pool are attached in the form of Excel File down below in Appendix A.

The survey questions asked from employees about the role of English language and communicative potential in managers are listed as follows: 
Table 1 . The survey questions

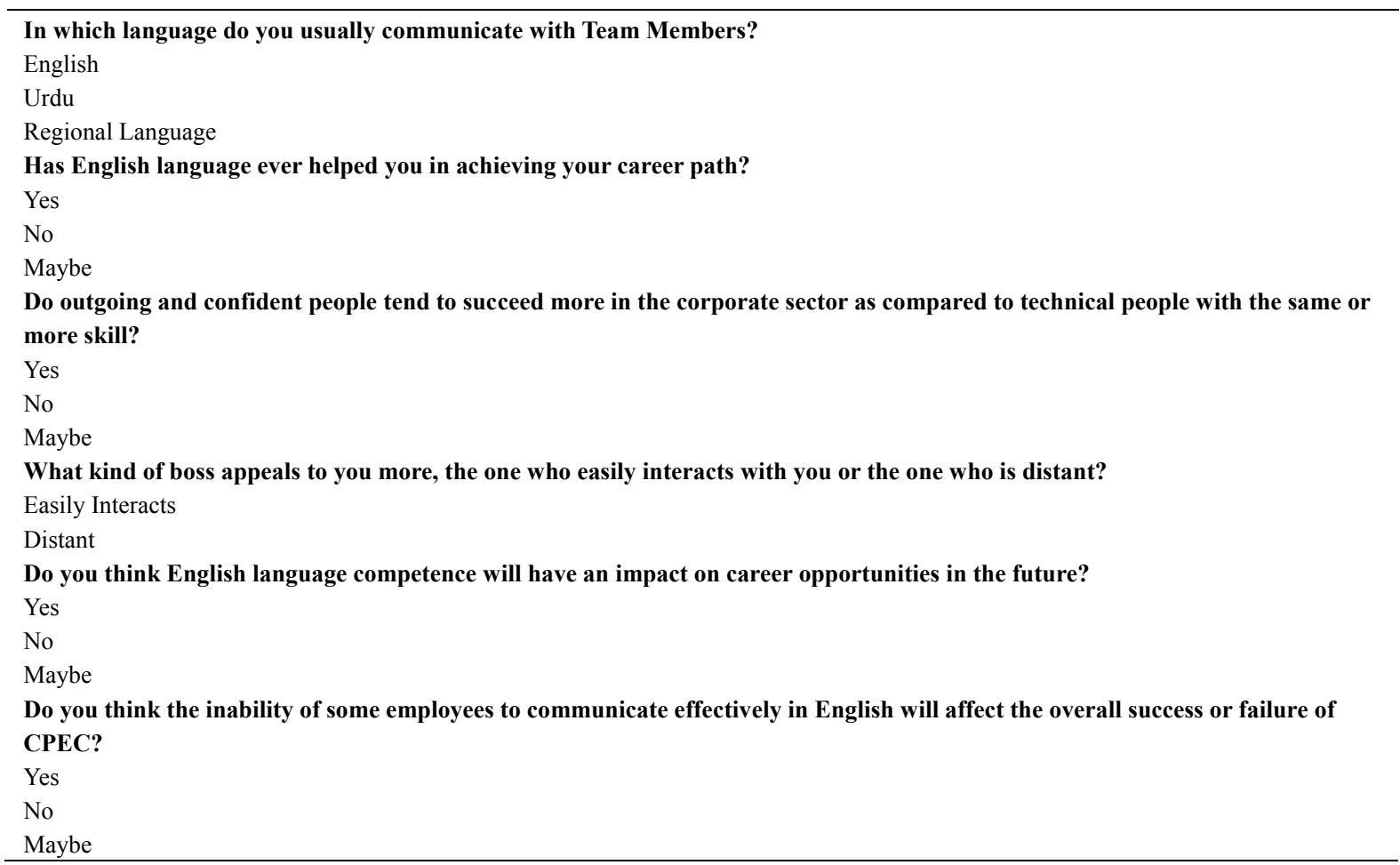

\subsection{Limitations in Methodology}

Although the methodology was well-planned and targeted to hit as many corporations as possible, the methodology lacked the quantification of reasons given by the employees in the selection of their answers. Due to the constraint of resources, the methodology was not able to address unstructured interviews for a deeper penetration into the psyche of the employees working in the corporate sector and the determination of the role of English language in everyday corporate environment (Emonds, 1976). That being said, the results generated by the questionnaire can help a more empirical approach towards the subject and quantify the responses into tier-based answers that can be related to similar studies done in environments like Dubai and Muscat, which closely resemble the multi-lingual, multi-cultural work place scenario experienced by professionals in corporate sector.

\section{Analysis}

The CPEC project is one of the most important projects in Pakistan and has challenged the modern world with some of the most difficult project deadlines and goals and expectations out of a very limited time window. In order to meet the goals and requirements of this particular project, the Pakistani work community has to match the potential and requirement of the Chinese counterparts in the work scenario and work on strategies required for the achieving of the said potential (Epstein, 2014). Communication is one of the most important needs of the teams that are taking part in this work scenario and teams need to communicate more often and more frequently with their team leads and team-mates in order to establish the kind of work ethic and environment that encourages growth and project commitment.

The Pakistani work force was found to be particularly interesting since most of the people communicate in more than 3-4 languages in their daily lives, and the work communication is not limited to the official language alone either $($ Etzion, 1984). The work communication medium between employees also differs based on the level of frankness, personal association, social norms and age and seniority differences between individuals. The questionnaires distributed between the companies (names listed in Appendix A), yielded the following responses with each question. The results are adequately addressed in the section afterwards.

\subsection{Questionnaire Results}

In which language do you usually communicate with Team Members? 


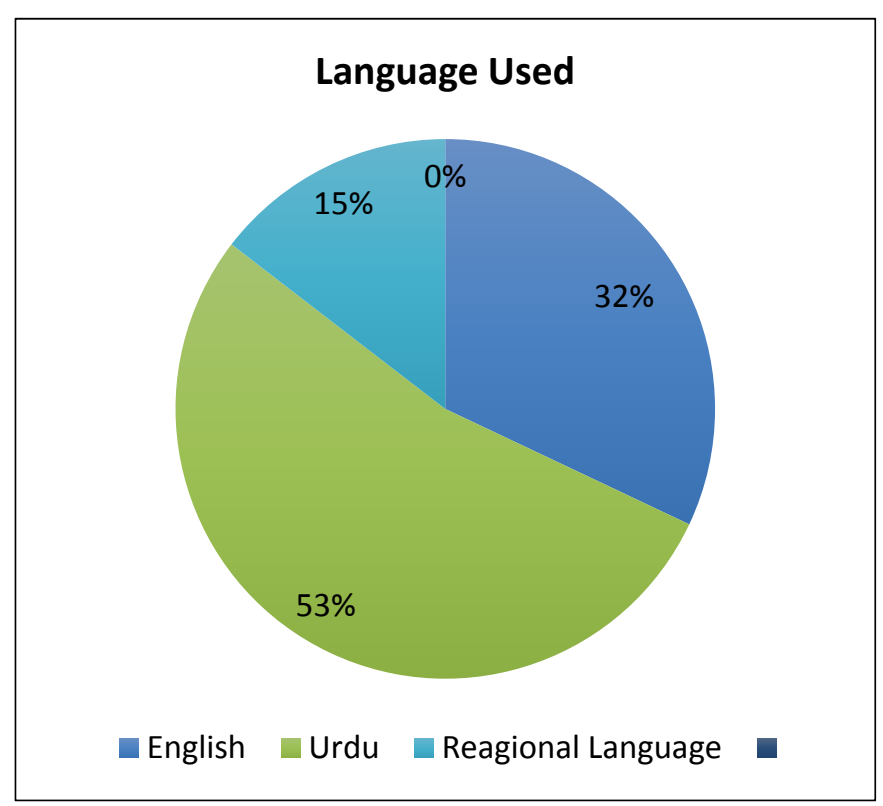

Figure 1. Language used for horizontal employee communication

Has English language ever helped you in achieving your career path?

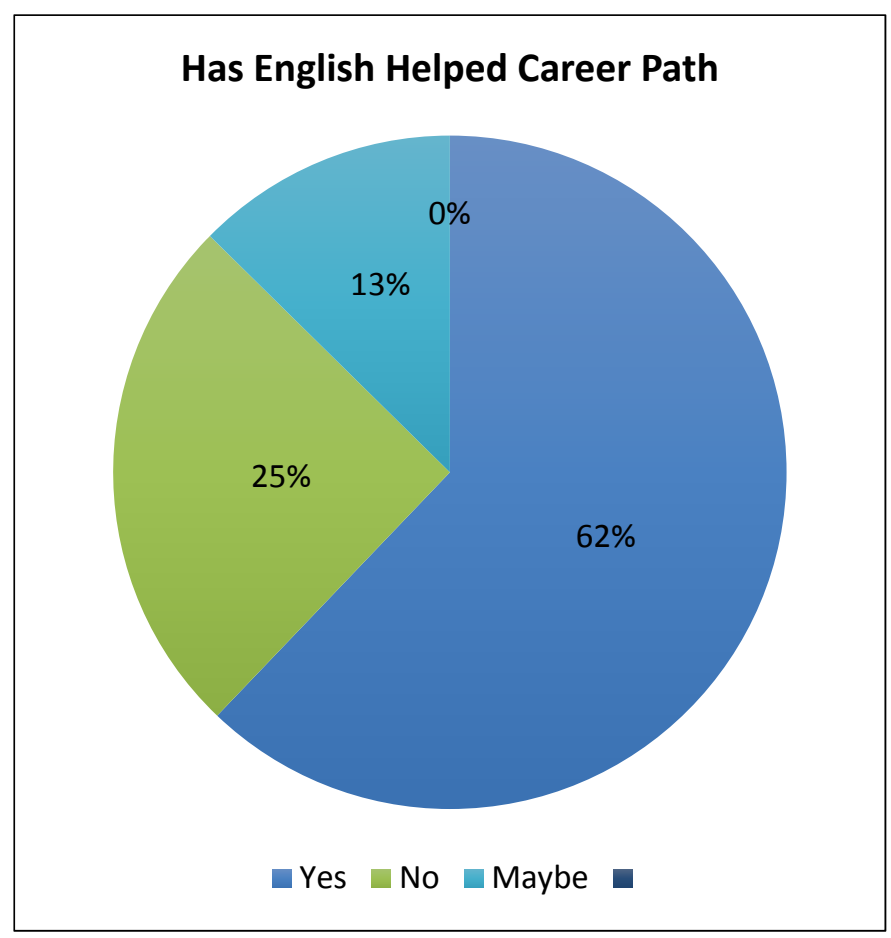

Figure 2. English vs career path success

Do outgoing and confident people tend to succeed more in the corporate sector as compared to technical people with the same or more skill? 


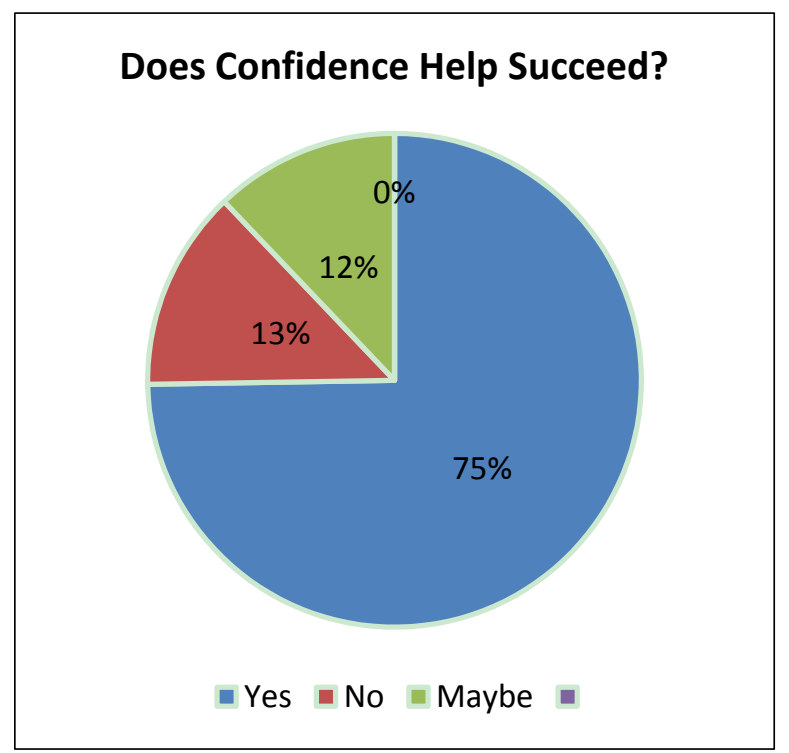

Figure 3. Confidence and job success

What kind of boss appeals to you more, the one who easily interacts with you or the one who is distant?

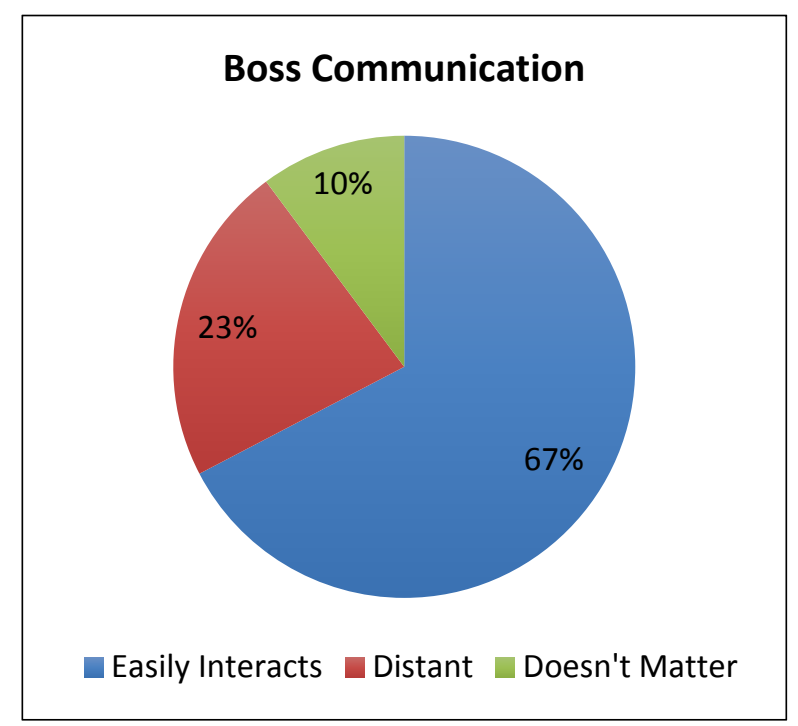

Figure 4. Boss communication and employee preferences

Do you think English language competence will have an impact on career opportunities in the future? 


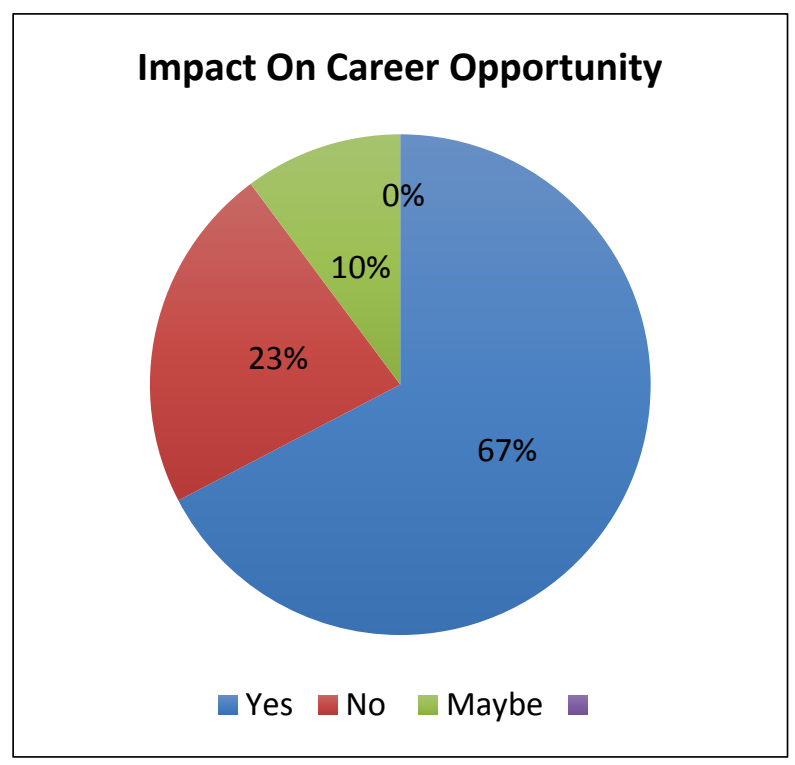

Figure 5. Impact of English on career opportunity

Do you think the inability of some employees to communicate in English will affect the overall success or failure of CPEC?

\section{ENGLISH AND CPEC SUCCESS}

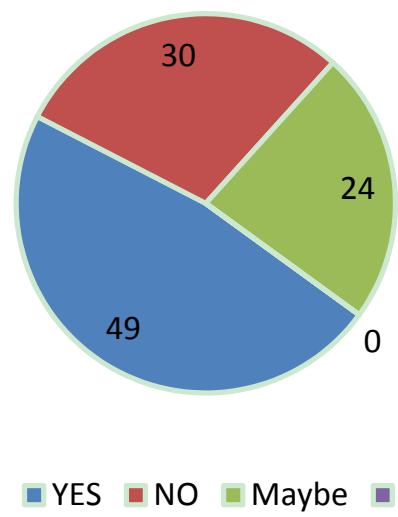

Figure 6. English and CPEC success

\subsection{Analysis}

\subsubsection{Discussion of Results}

The questionnaire was distributed through a google form and was filled by almost 103 participants from various companies. The responses collected for each question have been visually represented in the form of pie charts shown above.

\subsubsection{Mode of Communication}

As the dataset shows, the first question evaluated the use of the various modes of commutation in the work place, which differed from official language or the English language, the common language or lingua franca, which in the context of Pakistan is the Urdu language and finally the regional language which showed some cultural backdrop as well in the work place (Favell, 2007). Considering almost 15 work places in the projects associated with the CPEC, we found that almost $53 \%$ of the employees conducted all forms of horizontal communication or 
same tier communication with their fellow team mates in the Urdu language in order to keep the communication gap at a minimum in the horizontal forms of communication. Therefore, we can say that inter-communication between the employees is both informal and highly effective since it does not lack the use of a medium (Bagarić, 2007). Interestingly, about $32 \%$ of the people agreed to using English as their base of communication. This result is particularly intriguing considering the fact that a big population of individuals use Urdu as their medium of communication. When the datasets were compared with the dataset formulated by studies of Anwer (2016), it was found that the elements of code switching and cultural and formal understanding are at play. When people are formal with an employee, they tend to use the official register or English language to communicate, but this behavior changes when the people have to communicate a particularly complex situation and their linguistic ability is not able to justify that scenario in the official language (Gumperz, 1982). In such a case, people change their medium of communication or language of communication with the interlocutor, thereby preserving the message's efficiency and ensuring the delivery of the message as compared to being "formal" and "competent" by the use of the English language. The process of the said communication can be explained by the use of the smart chart given below:

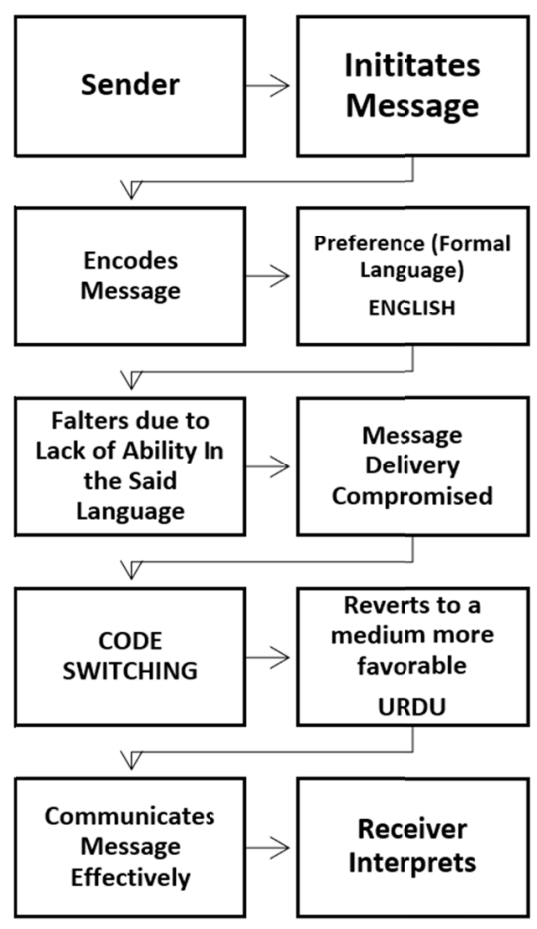

Figure 7. Code switching paradigm

In the corporate setting, it is more important for the employees to have access to information and to be able to effectively communicate with each other than to simply be able to speak in English, therefore, code switching is a very common element.

\subsubsection{English as Career Path Accelerator}

Considering the second result, almost $62 \%$ of the employees agreed that the English language had helped in the climb of their career path in the corporate sector. Such a high response indicates that the people have a higher chance of career success in the corporate sector, when they feel confident in their linguistic ability due to the English language. The results of this particular question address the importance of the medium of English language in the context of communicative competence (Bachman, 1996). Therefore, it also considers the importance of the medium for the career path and influence of the employee with competence in the said skills. In contrast to the $62 \%$ of the employees who agreed on the importance of the English language, about $25 \%$ of the majority disagreed about the importance of the English language in general. Therefore, we can say that despite the importance placed over the English language globally as a medium, about a quarter of the sample population from the corporate sector felt that the other languages could also be used for the communication and thereby did not necessitate the need of the medium. These results reaffirm our initial declaration of the superfluous "official" 
importance of the English language as a medium of correspondence in Pakistan, which is in essence, a linguistic annexation on behalf of the British in the colonial era, that has transcended into the cultural paradigm of post-colonial nations like Pakistan, India, Sri Lanka etc.

\subsubsection{Confidence as Function of Communicative Competence}

While the second dataset (Figure 2) addressed the importance of the English language as a medium, the third dataset tried to approach the question of communicative competence as a pre-requisite in the determination of career success and growth in the corporate sector. The question does not directly relate to the concept but reiterates the same in a manner that could help collect intelligent assured responses. As shown by the data set of the third figure, it is found that about a large majority, about $75 \%$ of the people in the corporate sector of Pakistan, especially the ones working the CPEC charter agree that confidence plays a major role in the job success of a person in Pakistan. This confidence is in essence, a function of the communicative competence of the person involved and enumerates the capabilities of the person as a competent communicator within carious organizational roles. According to Habermas's (1970) definition, a lack of confidence can be interpreted as a weakness in the understanding of the principles of communication required for effective delivery of the message in various settings. On the basis of the said definition and the correlation with the obtained graphical results, we observe that communicative competence is one of the most important requirements of the career progress in Pakistan and one of the most important reasons of career acceleration. It enables the user to have access to many more opportunities and better challenges as camporee to less competent communicators. This competence is not limited to their ability in the English language which was evaluated in the previous dataset (Figure 2), but their ability as communicator in different contextual and linguistic scenarios, as mentioned by Hymes definition in the literature.

\subsubsection{Leadership and Communicative Competence}

Moving towards the next dataset or Figure 4, the question of Leadership and Communicative competence are addressed. The dataset addressed the important question of "What kind of boss appeals to you more, the one who easily interacts with you or the one who is distant?". This question tries to find out employee reactions about the communicative competence of leaders and team-leads in various scenarios and tries to find whether the work or corporate culture in Pakistan supports communicative aspect of leadership or prefers a more autocratic managerial kind of leadership approach. The dataset demonstrated that about $67 \%$ of the population preferred bosses that communicated well with their employees. Basically, it shows that employer-employee communication or boss-employee communication which is in essence a vertical communication is supported by the employees in almost all-tiers of leadership or corporate structure for general motivation and drive towards daily goals. As discussed in the literature, relationships within the company are a measure of the success of the company and these relationships are built over the communication of the company (Bachmann, 1996). If the vertical communication between the bosses and the employees is streamlined, we find that the corporate success of the company is much higher. Although previously studied datasets for similar work environments in America and Western nations gave similar results, this study enumerates the benefits of such competence on behalf of the leaders for the first time in a Pakistani corporate setting. In contrast, about $23 \%$ of the employees preferred distant bosses.

Therefore, it is indicated that about a quarter of the employees in Pakistani corporate sector prefer reclusive bosses that do not interfere in the low-tier social circle or processes as long as the goals are being delivered. This kind of Laissez-Faire leadership style only works when the goals and processes being addressed by the team are being regularly delivered and intervention by the employer can actually negatively impact the overall project performance. In such a scenario, the communicative competence on behalf of the employer is not extra communication but well-structured meaningful and reserved communication.

\subsubsection{English and Future Career Opportunities}

Similarly, the results obtained for the fifth data set or the dataset of the career opportunities relation to the English language was considered, it was found that $67 \%$ of the employees believed that the English language could create an impact over the overall career growth experienced by them in the future, especially considering the upcoming CPEC project. These employees' concern over the importance of their competence in the English language indicates that the awareness of the importance of the English language exists, but as indicated by the research done by Ahmed (2006), the schools and mediums of education for the impartment of the said education are lacking. Therefore, some sort of corporate schooling or pre-corporate schooling is required for the functional teaching of the English language for employees working in the corporate sector to ensure that the career progress and path taken by the employees is not hindered due to the absence of the required communicative and lingusitc 
competence elements (Bourdieu, 1977).

\subsubsection{CPEC Project and Importance of English Language}

Considering the multilingual setting, the employee responses regarding the CPEC project were also considered such that the possibility of the failure of communication between different employees due to lack of the presence of a common communicative medium was studied. Basically, the study raised the question of whether the lack of competence in the English language could possibly affect the overall progress of the CPEC project (Canale, 1983). It was quite a controversial question since it measured the entire success of the project on the competence of the communication between two multi-lingual multi-cultural pool of employees belonging to different backgrounds and tried to gain insight from the dataset provided by the employees themselves whether such a communication could have any impact over the success of the CPEC project overall. This result was not an unavoidable conclusion, but rather framed as an optional choice for the pool of 103 employees to consider the elements of success of the project and about an alarming 50\% agreed that the CPEC Project cannot be realized if the people working on the project are not competent enough in communication. Considering the fast-paced communication required for the project and the scope of the project, this alarming scenario must be addressed by the team leaders. The research conducted into the English Language Teaching and the Communicative Language Learning in Pakistan demonstrates that very little effort is conducted on part of the educational institutes on the learning of the functional language of communication in Pakistan and therefore a big pool of the Pakistani communicators is not able to address the needs of the communication in this sector (Canale, 1983). It is worth mentioning that about $30 \%$ of the employees felt confident that communicating alone could not result in the failure of the project but that can be considered as the realization of other equally important requirements such as funding and procurements taking preference.

\subsection{Recommendations}

Therefore, after detailed qualitative and quantitative analysis of both research conducted by previous authors and the independent research conducted by the team working on this paper, the following recommendations can be drawn for the various project managers working on the project, in order to make the CPEC project an organizational and coordination feasibility that is not hindered due to miscommunication or lack of communication.

Communicative Learning Training is essential for the people working in the corporate sector. Even though English language might not be used extensively in horizontal means of communication, a good competency in communicative process is essential for the flow of significant information to and from various employees. This process also streamlines the mentorship and inter-employee learning and training that is vital for teams with varying project requirements and multi-talented team setting (Canale, 1983).

Team Leaders must be competent in their communication regimes with the employees and engage more with them to ensure employee commitment to the goals of the project in short and the vision of the company in general; such frequent communication channels allow the company to have a more streamlined flow of information.

English Language is a must for the people working on the CPEC project considering that the alien workforce does not have a common lingua franca with the Pakistani work force and therefore requires some sort of "code" which is mutually understood. Internationally, the English language is the agreed upon code of communication between international dealings and therefore, the English language can have a huge impact over the work force (in the hundreds of thousands) working on the project (Canale, 1983).

Modern means of communication in the form of cloud-based systems and computer based CRMS are an important feature of such projects so that all form of information is easily accessible to different employees working on the same domain. Such computerized transfer of work details and information allows the bypassing of the human coding process of information into languages, and thereby allows the receiver a direct access of information. This is an efficient means of communication as compared to verbal means of informational exchange.

\section{Conclusion}

This research paper focuses over the development of the parameters that adequately defines the meaning of communicative competence in the Pakistani corporate sector's perspective and use the said definition for the evaluation of the job prospects, career opportunities and motivation of employees. The communicative competence's role in the progress of employees was evaluated on the basis of questionnaires collected in the form of an unbiased, anonymous drive. The results obtained allowed us to formulate some important 
recommendations for the success of the CPEC mega project and overall improvement of the employees working in the corporate sector of Pakistan.

\section{References}

Ahmad, S., \& Rao, C. (2013). Applying communicative approach in teaching English as a foreign language: A case study of Pakistan.

Anwer, A., \& Gill, A. (2016). Effect of Communicative Competence in English on Employees' Promotions in Cellular Companies of Pakistan.

Bachman, L. F., \& Palmer, A. S. (1996). Language testing in practice: Designing and developing useful language tests (Vol. 1). Oxford University Press.

Bagarić, V., \& Djigunović, J. M. (2007). Defining communicative competence. Metodika, 8(1), 94-103.

Black, R., Engbersen, G., \& Okólski, M. (Eds.). (2010). A continent moving west? EU enlargement and labor migration from Central and Eastern Europe. Amsterdam University Press. https://doi.org/10.1515/9789048510979

Blasková, M., \& Blasko, R. (2010). Motivation policies in the public sector of the Slovak Republic. Viesoji Politika ir Administravimas, 32.

Bourdieu, P. (1977). The economics of linguistic exchanges. Information (International Social Science Council), 16(6), 645-668. https://doi.org/10.1177/053901847701600601

Bourdieu, P. (1991). Language and symbolic power. Harvard University Press.

Burda, M. C., \& Profit, S. (1996). Matching across space: evidence on mobility in the Czech Republic. Labour Economics, 3(3), 255-278. https://doi.org/10.1016/S0927-5371(96)00013-9

Burešová, V., \& Dvořáková, L. (2015, October). Corporate Performance Measures of Intellectual Property and Innovations (p. 36). In ECMLG2015-11th European Conference on Management Leadership and Governance: ECMLG2015. Academic Conferences and publishing limited.

Canale, M. (1983). From communicative competence to communicative language pedagogy. Language and Communication, 1(1), 1-47.

Canale, M., \& Swain, M. (1980). Theoretical bases of communicative approaches to second Language Teaching and Testing. Applied Linguistics, 1(1), 1-47. https://doi.org/10.1093/applin/I.1.1

Chakravarthy, B. S. (1986). Measuring strategic performance. Strategic Management Journal, 7(5), 437-458. https://doi.org/10.1002/smj.4250070505

Chomsky, N. (1969). Linguistics and Politics-Interview. New Left Review, 57, 21.

Chow, C. W., Deng, F. J., \& Ho, J. L. (2000). The openness of knowledge sharing within organizations: A comparative study of the United States and the People's Republic of China. Journal of Management Accounting Research, 12(1), 65-95. https://doi.org/10.2308/jmar.2000.12.1.65

Chughtai, A. A. (2008). Impact of job involvement on in-role job performance and organizational citizenship behaviour. Journal of Behavioral and Applied Management, 9(2), 169.

Crystal, D. (2012). English as a global language. Cambridge university press. https://doi.org/10.1017/CBO9781139196970

Deshpandé, R., Farley, J. U., \& Webster Jr, F. E. (1993). Corporate culture, customer orientation, and innovativeness in Japanese firms: A quadrat analysis. The Journal of Marketing, 23-37. https://doi.org/10.1177/002224299305700102

Dhir, K. S. (2005). The value of language: concept, perspectives, and policies. Corporate Communications: An International Journal, 10(4), 358-382. https://doi.org/10.1108/13563280510630151

Edirisingha, P., Rizzi, C., Ming, N. I. E., \& Rothwell, I. (2007). Podcasting to provide teaching and learning support for an undergraduate module on English language and communication. Turkish Online Journal of Distance Education, 8(3).

Emonds, J. E. (1976). A transformational approach to English syntax: Root, structure-preserving, and local transformations. Academic Press Inc.

Epstein, M. J., \& Buhovac, A. R. (2014). Making sustainability work: Best practices in managing and measuring corporate social, environmental, and economic impacts. Berrett-Koehler Publishers. 
Etzion, D. (1984). Moderating effect of social support on the stress-burnout relationship. Journal of Applied Psychology, 69(4), 615. https://doi.org/10.1037/0021-9010.69.4.615

Favell, A., Feldblum, M., \& Smith, M. P. (2007). The human face of global mobility: A research agenda. Society, 44(2), 15-25. https://doi.org/10.1007/BF02819922

Giles, H., Taylor, D. M., \& Bourhis, R. (1973). Towards a theory of interpersonal accommodation through language: Some Canadian data. Language in Society, 2(2), 177-192. https://doi.org/10.1017/S0047404500000701

Gumperz, J. J. (1982). Discourse strategies (Vol. 1). Cambridge University Press. https://doi.org/10.1017/CBO9780511611834

Habermas, J. (1970). Towards a theory of communicative competence. Inquiry, 13(1-4), 360-375. https://doi.org/10.1080/00201747008601597

Hymes, D. (1972). On communicative competence. Sociolinguistics, 269-293.

Light, J. (1989). Toward a definition of communicative competence for individuals using augmentative and alternative communication systems. Augmentative and Alternative Communication, 5(2), 137-144. https://doi.org/10.1080/07434618912331275126

Marschan, R., Welch, D., \& Welch, L. (1997). Language: The forgotten factor in multinational management. European Management Journal, 15(5), 591-598. https://doi.org/10.1016/S0263-2373(97)00038-8

Phase, I. I. (2005). Educating the engineer of 2020: Adapting engineering education to the new century. National Academies Press.

Spitzberg, B. H. (1988). Communication competence: Measures of perceived effectiveness (pp. 67-105). A handbook for the study of human communication: Methods and instruments for observing, measuring, and assessing communication processes.

Tsui, A. B., \& Tollefson, J. W. (2008). Language policy, culture, and identity in Asian contexts. Language Policy, $12(2)$.

\section{Appendix A}

\section{1) Companies Associated with CPEC (Interview Pool):}

2) Engo Power

3) Attock Gen Limited

4) Halmore Power

5) Laraib Energy Limited

6) Sapphire

7) SPL

8) China Petroleum Pipeline Bureau

9) Haier Electrical Applications Corporation Ltd.

10) Huawei Technology Co., Ltd.

11) TBD

12) China Railway-China North Industries Group Corporation (CR-NORINCO)

13) Huaneng Shandong Ruyi (Pakistan) Energy (Private) Ltd.

14) Hydrochina International Engineering Co. Ltd.

15) UEP Wind Power (PVT) Ltd.

\section{Copyrights}

Copyright for this article is retained by the author, with first publication rights granted to the journal.

This is an open-access article distributed under the terms and conditions of the Creative Commons Attribution license (http://creativecommons.org/licenses/by/4.0/). 